\title{
SURGICAL CROWN LENGTHENING: A 12-MONTH STUDY - RADIOGRAPHIC RESULTS*
}

\author{
Daniela Eleutério DINIZ ${ }^{1}$, Kalizia Marcela OKUDA ${ }^{1}$, Clarissa Ribeiro FONSECA ${ }^{1}$, Marly Kimie Sonohara GONZALEZ ${ }^{2}$, \\ Sebastião Luiz Aguiar GREGHI ${ }^{3}$, Accácio Lins do VALLE ${ }^{4}$, José Roberto Pereira LAURIS ${ }^{5}$
}

\begin{abstract}
1- DDS, Undergraduate student, Department of Periodontology, Dental School of Bauru, University of São Paulo, Bauru, SP, Brazil.
2- DDS, MSc, Associate Professor, Department of Dentistry, State University of Maringá, Maringá, PR, Brazil.

3- DDS, MSc, PhD, Associate Professor, Department of Periodontology, Dental School of Bauru, University of São Paulo, Bauru, SP, Brazil.

4- DDS, MSc, PhD, Associate Professor, Department of Prosthodontics, Dental School of Bauru, University of São Paulo, Bauru, SP, Brazil.

5- MSc, PhD, Associate Professor, Department of Pediatrics, Orthodontics and Public Health, Dental School of Bauru, University of São Paulo, Bauru, SP, Brazil.
\end{abstract}

Corresponding address: Marly K. Sonohara Gonzalez - Al. Dr. Octávio Pinheiro Brisolla, 9-75, Disciplina de Periodontia, 17012-901, Bauru-SP, Brasil - Phone: 5514 3235-8366 e-mail: clinica@marlysonohara.odo.br

*This paper is based on a thesis submitted in partial fulfillment of the requirements for granting a PhD degree from the Dental School of Bauru, SP, Brazil.

Received: September 18, 2006 - Modification: February 05, 2007 - Accepted: May 28, 2007

\begin{abstract}
$O$

bjective: The purpose of this study was to perform a radiographic follow-up evaluation after a 12-month healing period, following crown lengthening surgery.

Material and methods: Twenty-three periodontally healthy subjects (mean age 32.5 years) that required crown lengthening surgery in premolars were recruited. In a total of 30 premolars, full thickness flaps, osseous resection, and flap suturing were performed. The restorative margin was defined in the pre-surgical phase and maintained unaltered during the healing period, serving as a reference point. Standardized bitewing radiographs were taken before and after osseous reduction, and at 2, 3, 6, and 12-month healing periods.

Results: Intact lamina dura was observed at both mesial and distal alveolar crests only from the 3rd month. At 12-months, all alveolar crests presented lamina dura. The overall mean distance from the restorative margin to the alveolar crest achieved after osseous resection was $3.28 \pm 0.87 \mathrm{~mm}$ at mesial and $2.81 \pm 0.51 \mathrm{~mm}$ at distal sites. No significant radiographic changes in the bone crest were observed during a 12-month healing period.

Conclusion: The findings of this study suggest that the radiographic proximal bone level observed on bitewing radiographs following crown lengthening surgery can be used as a reference to predict the future level of the healed alveolar crest.
\end{abstract}

Uniterms: Oral surgical procedures; Wound healing; Bitewing radiography.

\section{INTRODUCTION}

Surgical crown lengthening is a routinely performed treatment ${ }^{3,8,10,11,15}$, but little is known about the radiographic changes in the alveolar bone crest over time. Crown lengthening involves the surgical removal of hard and soft periodontal tissues to gain supracrestal tooth length, allowing longer clinical crowns ${ }^{8}$ and reestablishment of the biologic width ${ }^{5,8}$.

In a human histological investigation, Wilderman, et al. ${ }^{17}$ (1970) described the healing process of the vestibular bone at 0 hour, 1-, 2-, and 3-week, and 1-, 2-, 3-, 6-, 9- and 12-month following osseous surgery. Microscopic evidences indicated more bone loss and less bone repair occurred in the thin alveolar bone specimens. Maximum bone repair and almost complete anatomic restoration of the operated bone would be achieved if the preoperative bone was the thick cancellous type with many marrow spaces.

Radiographic methods are commonly used to assess periodontal bone changes in clinical trials. On subsequent radiographic examinations, bone loss or gain may be assessed by comparing the subsequent radiographs with the initial radiographs ${ }^{13}$. There is no prospective clinical study available reporting the radiographic alterations in the proximal alveolar crest over 6 months after osseous resection.

Dibart, et al. ${ }^{4}$ (2003) retrospectively evaluated the outcome of crown lengthening surgery prior to final crown placement on mandibular molars. The results indicated that $40 \%$ of the molars developed a furcation lesion at 5 years after crown cementation. An initial distance from the furcation entrance to the margin of the restorative margins $<4 \mathrm{~mm}$ eventually developed a furcation involvement, while 
none of the molars $>4$ mm developed a furcation involvement. No evaluation was made of the mesial and distal alveolar crest.

The purpose of the present study was to make a further assessment of alterations in the proximal alveolar crest over a 12-month healing period from the post-osteotomy osseous level established in surgical crown lengthening.

\section{MATERIALAND METHODS}

The study protocol was approved by the local ethics committee. Each patient was provided with information about the study and indicated willingness to participate by providing written informed consent. The study population consisted of 23 periodontally healthy patients ( 7 men, 16 women), 20 to 45 years of age (mean age, 32.5 years) referred to crown lengthening surgery on one or two premolar teeth. The indication for crown lengthening included insufficient clinical crown length for retention of the reconstructions, deep subgingivally-located carious lesions, crown and root fractures, preexisting deep preparation margins, perforations during endodontic therapy, and root resorptions ${ }^{2}$. Medical and dental histories were reviewed and no contra-indications to surgical therapy were noted.

A total of 30 premolars were identified for inclusion in the study. All patients were subjected to initial periodontal therapy including oral hygiene instructions, as well as scaling/root planing and removal of marginal irritants. For radiographic examination, the bite-wing bite block RinnÒ (Rinn Corporation, Elgin, IL, USA) was duplicated in colorless acrylic resin to obtain a bite block for each area to be evaluated. At a pre-surgical appointment, an occlusal bite in acrylic resin Duralay ${ }^{\circledR}$ (Reliance Dental Mfg Co., Worth, IL, USA) was taken on the duplicated bite block to standardize the subsequent radiographs ${ }^{16}$. Standardized bite-wing radiographs were taken using KodakÒ film (Ektaspeed, Eastman Kodak Co, Rochester, NY, USA), a fixation device for standardized exposure geometry at 70 $\mathrm{kVp}$ and $0.8 \mathrm{~mA}$, with exposure time of 0.7 seconds, and standardized automatic processing conditions (Perio-pro, Air Technique Inc., New York, USA).

Once the restorative margin was defined, only one periodontist performed the crown lengthening surgery ${ }^{9}$. Each case included intrasulcular and/or reverse bevel incisions and elevation of full-thickness flaps on the buccal and lingual aspects. Subsequently, osteoplasty and ostectomy were performed using rotary and hand instruments to place the alveolar bone at a level at least $3 \mathrm{~mm}$ from the apical extent of the planned restorative margin ${ }^{8}$. To allow sufficient coverage of the interdental bone, attempts were made to position the flap margins at least $2 \mathrm{~mm}$ coronal to the bone crest after suturing. No periodontal dressing was used.

All patients were prescribed a non-steroidal antiinflammatory analgesic and twice daily $0.12 \%$ chlorhexidine gluconate rinses for 2 weeks. Sutures were removed 7 and 10 days postoperatively and a plaque control regimen was instituted. New, well-adapted provisional crowns were fabricated and cemented 2 weeks postsurgically. No further modification of the tooth preparation was allowed during the 12 months of the study in order to preserve the restorative margins (RM) as references points for measurement ${ }^{7}$.

All patients were maintained on a plaque control program which included prophylaxis and reinforced oral hygiene. Radiographic examinations were repeated at 2, 3, 6 and 12 months following surgery.

\section{Radiographic Assessment}

Under standardized viewing conditions in a dark room, the presence of intact lamina dura was observed at mesial (M) and distal (D) reduced alveolar crest around the premolar. Radiographic recording was performed twice by one observer, with a 2 -week time period between examinations ${ }^{1}$.

Digital images of all radiographs were obtained by photographic digital camera (Coolpix 5700 Nikon $^{\circledR}, 5$ mega pixels) and stored in a computer. Using a computer program (Image ${ }^{\circledR} 1.34 \mathrm{~s}$; US National Institutes of Health, Bethesda, MD, USA), each image was converted to 8-bit grayscale and to $200 \%$ magnification level ${ }^{14}$. The distance from RM to the marginal alveolar crest was measured at $\mathrm{M}$ (Figure 1) and/or D premolar sites. The marginal proximal bone level was deemed to be at the point along the root surface, where a periodontal ligament of even radiographic width could be observed. All measurements were made in a darkened room to facilitate visualization of the images on a video monitor. The mean between two readings was taken with a 15 -day time interval ${ }^{14}$.

\section{Statistical Analysis}

Data obtained for each type of site were averaged and

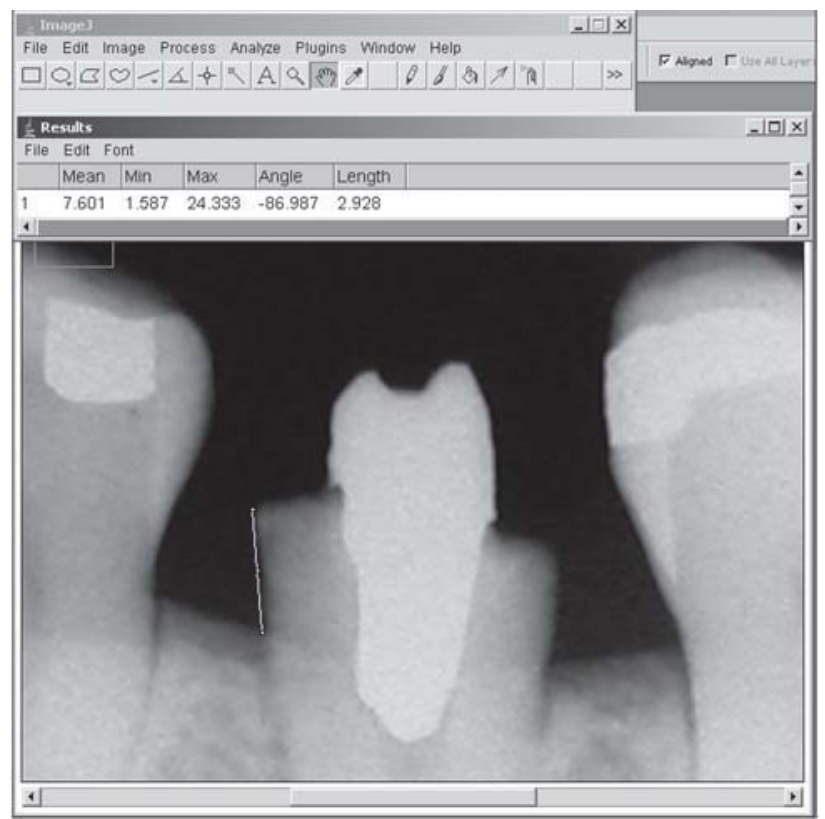

FIGURE 1- Using Image ${ }^{\circledR}$ software, a parallel straight line (yellow line) to the root surface was drawn over the digital image to measure the distance from restorative margin to the marginal alveolar crest at mesial premolar site 
assessed for differences between baseline and 2, 3, 6 and 12 months. The data were analyzed by repeated measurement analysis of variance (ANOVA) to determine presence of an overall effect, separately for M and D sites. Tukey's test was used to determine which time point differed significantly. The level of significance was set at 0.05 .

\section{RESULTS}

No post-surgical complications were observed. One patient did not show up for the 2-month examination and another at 12 months. Two individual devices were not adjusted because of tooth movement at 1- and 12-month. Thus, by the end of the study, there were 19 patients, and 26 premolars were evaluated at all times.

A total of 46 sites were available for radiographic assessment. No intact lamina dura was observed at the M and D alveolar crests at the 2-month period (Table 1). At 3month, its presence was evidenced only at one $(4.3 \%) \mathrm{M}$ and one $(3.7 \%) \mathrm{D}$ alveolar crest. The percentage of lamina dura increased to $60.9 \%$ (14) and $66.7 \%$ (18), at $\mathrm{M}$ and $\mathrm{D}$ alveolar crests, respectively, at 6-month. At 12-month, all M and $\mathrm{D}$ alveolar crests showed the presence of intact lamina dura (Figure 2).

Using the radiographic reading obtained with the Image $\mathrm{J}^{\circledR}$ software, the mean distance from RM to the alveolar crest is shown in Table 2. A significant reduction was observed following osseous resection at both $\mathrm{M}$ and $\mathrm{D}$ sites. The mean amount of osseous reduction was $1.2 \mathrm{~mm}$ at $\mathrm{M}$, and $1.3 \mathrm{~mm}$ at D sites. During the healing phase, a comparison of the radiographic bone height readings revealed that bone level changes not were statistically significant.

\section{DISCUSSION}

Radiographs are unique as source of data because they provide a permanent visual record of the bone support, allowing linear measurements of the structures to be obtained $^{13}$. In the present study, the radiographic assessment of the lamina dura and distance between bone crest and RM was performed in standardized bite-wing radiographs. Intact lamina dura was observed in only two alveolar crests at the 3 -month period (Table 1). From this time period on, radiographic evidence of its presence began to increase and, at 12 months, intact lamina dura was observed in all alveolar crests (Figure 2). The lamina dura appears as a dense continuous white line that represents more densely packed bone with fewer and/or smaller marrow spaces than in the neighboring bone. Its appearance is determined both by the shape and position of the tooth root in relation to the $\mathrm{x}$-ray beam, and by the integrity of the bone lining the tooth socket and alveolar crest $^{6}$. Therefore, the radiopacity of the crestal lamina dura results from the $\mathrm{x}$ ray beam passing tangentially through the width of the cortical bone on the interdental crest ${ }^{12}$. From the outcomes obtained at 12-months, it may be suggested that the x-ray beam approximated this direction.

The major factors limiting the use of radiographic outcome measurements are geometric distortion and radiographic processing quality. The use of standardized methods, such as standardization of radiograph taking and processing, has reduced the effect of these errors on data from radiographs ${ }^{14}$. The radiographic examination is limited because the radiograph provides a restricted 2-dimensional representation of the 3-dimensional anatomy. As a result, many features of the anatomy are not apparent to the examiner during visual inspection of the radiograph. Interpretive radiography requires $30 \%$ to $60 \%$ of the mineral content of the bone to be lost in order to visualize a change in a radiographic image ${ }^{13}$. Thus, microscopic analyses represent an ideal method for evaluating bone healing.

Wilderman, et al. ${ }^{17}$ (1970) reported buccal periodontal tissue repair in humans after elevating a mucoperiosteal flap to gain access for the osseous resection. Bone necrosis occurred in the bone immediately beneath the reduced periosteal bone surface. If the buccal plate of bone over the tooth root was thin, resorption first occurred on the periodontal surface, and if the bone plate was thick, it began on bone surfaces facing marrow spaces and haversian systems. Resorption on the surgically reduced periosteal bone surface was delayed and occurred between 2 and 3 weeks postoperatively. Bone repair by osteoblastic activity reached its peak between third and fourth week after surgery. Very little apposition was apparent after 6 months. It was noted the replacement of immature bone by the intermediate type of bone at 6 months and its replacement by mature bone at 18 months after surgery. The authors reported that the local anatomy of the bone seemed to be determinant of the amount of bone loss following osseous surgery. If the preoperative bone was the thick cancellous type with many

TABLE 1- Number of alveolar crests and presence of intact lamina dura

\begin{tabular}{lcccc}
\hline & \multicolumn{3}{c}{ Mesial alveolar crest } & \multicolumn{2}{c}{ Distal alveolar crest } \\
& $\mathbf{N}$ & $\%$ & $\mathbf{N}$ & $\%$ \\
\hline 2 months & 0 & 0 & 0 & 0 \\
3 months & 1 & 4.3 & 1 & 3.7 \\
6 months & 14 & 60.9 & 18 & 66.7 \\
12 months & 21 & 100.0 & 25 & 100.0 \\
\hline
\end{tabular}


marrow spaces, maximum bone repair and almost complete anatomic restoration of the operated bone was achieved.

In the present study, comparison between initial and subsequent radiographs allowed detecting bone changes by measuring the distance between the bone crest and the RM (fixed reference point). When taking bitewing radiographs, it is possible to position the film more correctly and the $\mathrm{x}$-ray beam closer, perpendicularly ${ }^{6}$. Therefore, this technique was used to obtain an anatomically correct image of the alveolar bone position in relation to the RM and to evaluate changes in the bone crest for 12 months. Digitization was used to turn the radiographic image into a form that could be measured in a computer (Figure 1). In the pre-surgical radiographic image, the mean values of the linear measurements were $2.10 \mathrm{~mm}$ and $1.54 \mathrm{~mm}$, for $\mathrm{M}$ and $\mathrm{D}$ bone crest around premolars, respectively (Table 2). After osseous reduction, the linear measurements significantly increased to $3.28 \mathrm{~mm}(\mathrm{M})$ and $2.81 \mathrm{~mm}$ (D). During the repair processes, bone level at $\mathrm{M}$ and $\mathrm{D}$ alveolar crests showed no statistically significant bone loss. The characteristics of the proximal alveolar bone of the treated premolars were thick crests with many marrow spaces, resulting in less bone loss and more bone repair. It corroborates the histological repair described by Wilderman, et al. ${ }^{17}$ (1970).

From the studies found in the literature, only Dibart, et al. ${ }^{4}$ (2003) performed a radiographic assessment in mandibular molars following crown lengthening surgery. Bone loss at the furcation was observed in $40 \%$ of the molars. No evaluation on the proximal bone crest was performed. Lanning, et al. ${ }^{9}$ (2003) recorded clinical measurements of the bone level by means of transgingival probing, at 3 and 6 months following crown lengthening surgery. The mean difference in the direct bone level immediately after osseous resection and bone level at the 3-month examination was $0.77 \mathrm{~mm}$. This value represented the overall mean of the 4 sites (mesiobuccal, mesiolingual, distobuccal and distolingual) around the treated tooth. No comparative analysis can be made with the radiographic findings of the present study, as only 2 different sites - mesial and distal were evaluated.

The findings of the present study showed that radiographic changes in the proximal bone level were insignificant clinically from the osseous surgery up to the evidence of lamina dura.

\section{CONCLUSIONS}

The prospective radiographic assessment of the bone crest following crown lengthening surgery showed no significant changes in the proximal bone level in relation to the restorative margin over 12 months. This suggests that clinicians can predict the level of the healed proximal alveolar

TABLE 2- Distance from the restorative margin to the alveolar bone (mean values in $\mathrm{mm} \pm$ standard deviation)

\begin{tabular}{lll}
\hline & Mesial site & Distal site \\
\hline Pre-surgical & $2.10 \pm 1.37^{\mathrm{a}}$ & $1.54 \pm 0.65^{\mathrm{a}}$ \\
Surgical & $3.28 \pm 0.87^{\mathrm{b}}$ & $2.81 \pm 0.51^{\mathrm{b}}$ \\
2 months & $3.41 \pm 0.92^{\mathrm{b}}$ & $2.90 \pm 0.54^{\mathrm{b}}$ \\
3 months & $3.44 \pm 0.97^{\mathrm{b}}$ & $2.93 \pm 0.53^{\mathrm{b}}$ \\
6 months & $3.46 \pm 0.92^{\mathrm{b}}$ & $2.95 \pm 0.53^{\mathrm{b}}$ \\
12 months & $3.39 \pm 0.87^{\mathrm{b}}$ & $2.97 \pm 0.55^{\mathrm{b}}$ \\
\hline
\end{tabular}

Means followed by different letters in the same column are statistically different at $5 \%$ by the Tukey's test.

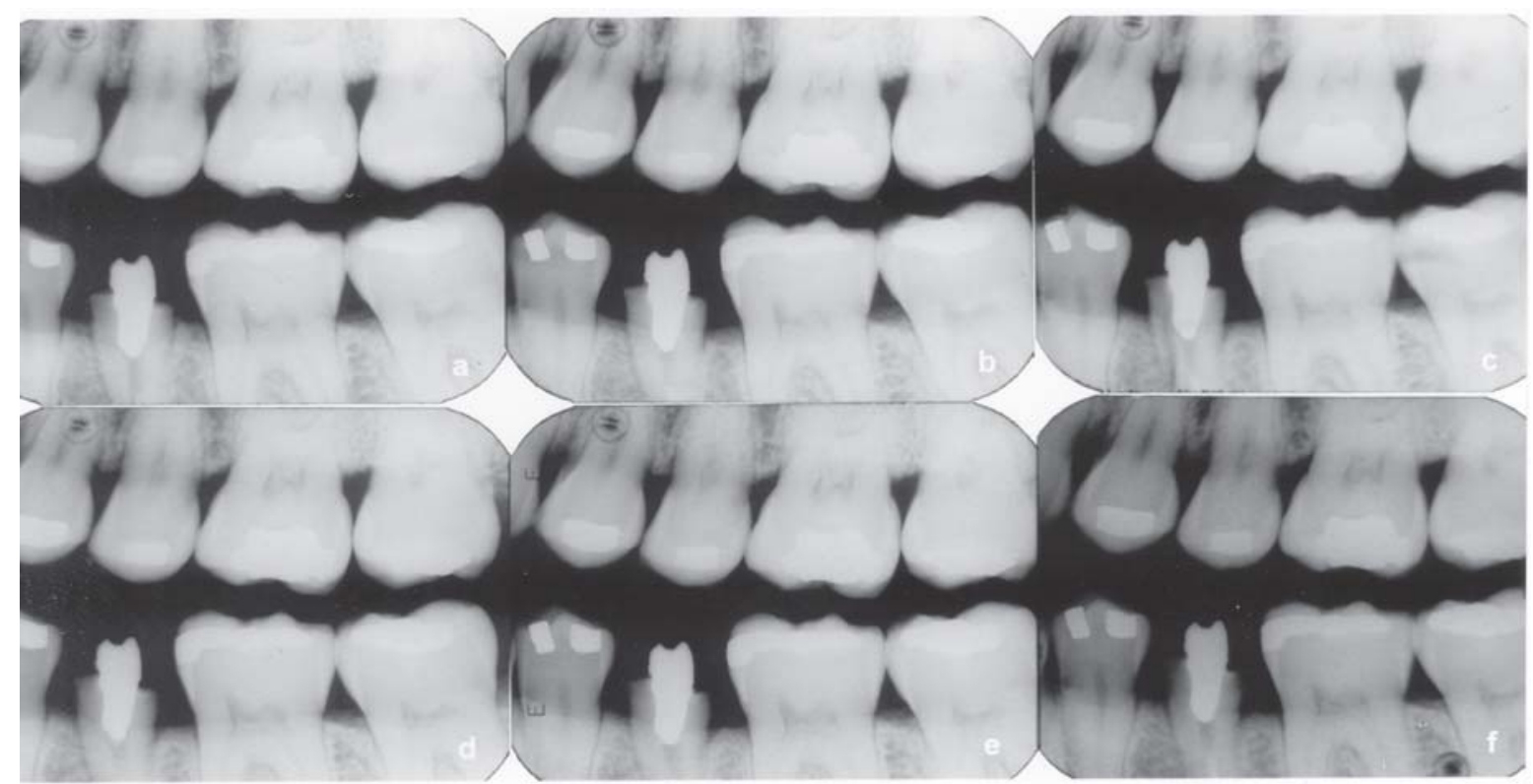

FIGURE 2- Bitewing radiographs of second mandibular premolar before (a) and after crown lengthening procedures (b), at 2- (c), at 3- (d), at 6- (e) and at 12-month periods (f). The presence of intact lamina dura is observed at mesial and distal alveolar crests, respectively, at 6 - and 12-month periods 
crest based on the radiographic bone level obtained after osseous resection.

\section{ACKNOWLEDGEMENTS}

The authors gratefully acknowledge the contribution and clinical assistance of Drs. Camila Soares, LuÍs Eduardo Butignon, Romão Mansano, Thiago Pegoraro.

\section{REFERENCES}

1- Ávila MAG. Análise das distorções da imagem radiográfica em diferentes aparelhos panorâmicos [dissertação]. Bauru (SP): Faculdade de Odontologia de Bauru, Universidade de São Paulo; 1996.

2- Brägger U, Lauchenauer K, Lang NP. Surgical lengthening of the clinical crown. J Clin Periodontol. 1992;19:58-63.

3- Deas DE, Moritz AJ, McDonnell HT, Powell CA, Mealey B. Osseous surgery for crown lengthening: a 6-month clinical study. J Periodontol. 2004;75:1288-94

4- Dibart S, Capri D, Kachouh I, Van Dyke T, Nun ME. Crown lengthening in mandibular molars: a 5-year retrospective radiographic analysis. J Periodontol. 2003;74:815-21.

5- Gargiulo AW, Wentz FM, Orban B. Dimensions and relations of the dentogingival junction in humans. J Periodontol. 1961;32:2617 .

6- Hausmann E. A contemporary perspective on techniques for the clinical assessment of alveolar bone. J Periodontol. 1990;61:149. 56

7- Herrero F, Scott JB, Maropis OS, Yukna RA. Clinical comparison of desired versus actual amount of surgical crown lengthening. J Periodontol. 1995;66:568-71.

8- Ingber FJS, Rose LF, Coslet JG. The "biologic width": a concept in periodontics and restorative dentistry. Alpha Omegan. 1977;70:625.

9- Lanning SK, Waldrop TC, Gunsolley JC, Maynard JG. Surgica crown lengthening: evaluation of the biological width. J Periodontol. $2003 ; 74: 468-74$

10 - Oakley E, Rhyu I, Karatzas S, Gandini-Santiago L, Nevins M, Caton J. Formations of the biologic width following crown lengthening in nonhuman primates. Int $\mathrm{J}$ Periodontics Restorative Dent 1999;19:529-41.

11 - Pontoriero R, Carnevale G. Surgical crown lengthening: a 12 month clinical wound healing study. J Periodontol. 2001;72:841-8.

12 - Reed BE, Polson AM. Relationships between bitewing and periapical radiographs in assessing crestal alveolar bone levels. J Periodontol. 1984;55:22-7

13 - Reedy MS. Radiographic methods in the evaluation of periodontal therapy. J Periodontol. 1992;63:1078-84.

14 - Schmitd LB. Avaliação radiográfica da reabsorção óssea periodontal por meio de valor de pixel e comparação com análise histopatológica [dissertação]. Bauru (SP): Faculdade de Odontologia de Bauru, Universidade de São Paulo; 2005.
15- Smukler H, Chaibi M. Periodontal and dental considerations in clinical crown extension: a rational basis for treatment. Int J Periodontics Restorative Dent. 1997;17:465-77.

16- Taba M Júnior. Monitoração da progressão da doença periodontal através de imagens radiográficas digitalizadas [dissertação]. Bauru (SP): Faculdade de Odontologia de Bauru, Universidade de São Paulo; 1995

17- Wilderman MN, Pennel BM, King K, Barron JM. Histogenesis of repair following osseous surgery. J Periodontol. 1970;41:551-65. 